Communications in Physics, Vol. 24, No. 3 (2014), pp. 247-256

DOI: $10.15625 / 0868-3166 / 24 / 3 / 3690$

\title{
MEASUREMENTS OF THE STRATOSPHERIC DENSITY AND TEMPERATURE PROFILES IN HANOI BY A RAYLEIGH LIDAR
}

\author{
NGUYEN XUAN TUAN, DINH VAN TRUNG, NGUYEN THANH BINH \\ Institute of Physics, Vietnam Academy of Science and Technology
}

BUI VAN HAI

Le Quy Don Technical University

E-mail: nxtuan@grad.iop.vast.ac.vn

Received 24 February 2014

Accepted for publication 04 April 2014 doi: 3690

\begin{abstract}
The molecular density and temperature profiles of the stratosphere in Hanoi are measured by a Rayleigh lidar. The profiles have the spatial resolution of $120 \mathrm{~m}$ and the temporal resolution of $1 \mathrm{~h}$. Their bottom height and top height are $20 \mathrm{~km}$ and $57 \mathrm{~km}$, respectively. The atmospheric molecule density profile is directly derived from the correction-range lidar signal. The temperature profile is deduced from the molecular density profile based on the assumptions of the hydrostatic equilibrium and the ideal-gas law. Lidar measurements show good agreement with the molecular density and the temperature profiles from the MSISE-90 atmospheric model. Maximum errors of the density and temperature are found to be $\pm 0.9 \%$ and $\pm 3.4 \mathrm{~K}$, respectively. The position and the temperature of the stratopause in Hanoi are determined to be about $49 \mathrm{~km}$ and $270 \mathrm{~K}$. Database of lidar in a long time might reveal the characteristic and the structure of the stratosphere in Hanoi, Vietnam.
\end{abstract}

\section{INTRODUCTION}

The stratosphere, an atmospheric layer located between about $15 \mathrm{~km}$ to $50 \mathrm{~km}$, has strongly interested in scientific community in some recent decades because it plays an important role to weather and climate in the synoptic and global scales [1] The stratosphere might directly affects to climate in the synoptic and global scales through: atmospheric planetary wave, atmospheric gravity wave, tide, jet stream ... Variations of the stratosphere affect also on climate of the troposphere and surface layers through processes: coupling and exchange processes. These processes relate tightly with extraordinary weather phenomena such as El Nino and La Nina [2]. Air density and temperature profiles of stratosphere are two main parameters to characterize the states and processes of stratosphere.

Two techniques probe the density and temperature profiles consist of: in situ sensor (balloonradiosonde and rocketsonde) and remote sensing. The radiosonde technique is limited by the maximum measuring height of balloon (about $30 \mathrm{~km}$ ) and the rocketsonde become too expensive for routine observation. In addition, they only get desultory temporal and spatial distributions. Since lidar (light detection and ranging) was applied to study the atmosphere, it has emerged a powerful

(C)2014 Vietnam Academy of Science and Technology 
remote sensing technique to study the stratosphere with high temporal and spatial resolution measurements. The stratospheric temperature profile measurements using Rayleigh lidar technique were firstly carried out by A. Hauchecorne and M. Chanin (1980) [3]. The accuracy and reliability of this lidar technique were continuously improved by T. Shibata et al. (1986) [4], Micheal R. Gross et al. (1997) [5], W. N. Chen et al (2004) [6], Jaya Khanna et al. (2012) [7]. By this method, the molecule density can be derived by the inversion from lidar signal, and the temperature profile can be determined from molecule density profile based on the assumptions of the ideal gas and hydrostatic equilibrium. Nowadays, the temperature measurements using Rayleigh lidar has provided accurate and reliable data for studying the trend and characteristic of the stratosphere.

A Rayleigh lidar probing the stratosphere has developed at Institute of Physics, Hanoi. In this paper, we present designs, specifications and lidar signal measurements. The molecule density and the temperature profiles of the stratosphere derived from lidar measurement compared with the MSISE-90 atmospheric model to validate our results. Errors of measurements are also presented and discussed in detail.

\section{LIDAR SYSTEM SETUP}

Our Rayleigh lidar system, located at Hanoi $\left(21^{\circ} 2^{\prime} 0^{\prime \prime} \mathrm{N}, 105^{\circ} 51^{\prime} 00^{\prime \prime} \mathrm{E}\right.$, about $20 \mathrm{~m}$ above sea water level), Vietnam, is designed consisting of transmitter and receiver based on mono-static biaxial configuration (the schematic block is shown in Fig. 1). The transmitter used the second harmonic Nd:YAG pulsed laser at the wavelength of $532 \mathrm{~nm}$ and the repetition of $10 \mathrm{~Hz}$. The laser beam, which is expanded 3 times by a beam expander in order to decrease divergence, is directed vertically to the sky by a steering mirror. Backscattering light (lidar signal) from the atmosphere is collected by a Schmidt-Cassegrain optical telescope with the diameter of $25 \mathrm{~cm}$. These backscattering signals are filtered through a narrow band interference filter with the fullwidth at half-maximum (FWHM) of $1 \mathrm{~nm}$ to reject light outside bandpass.

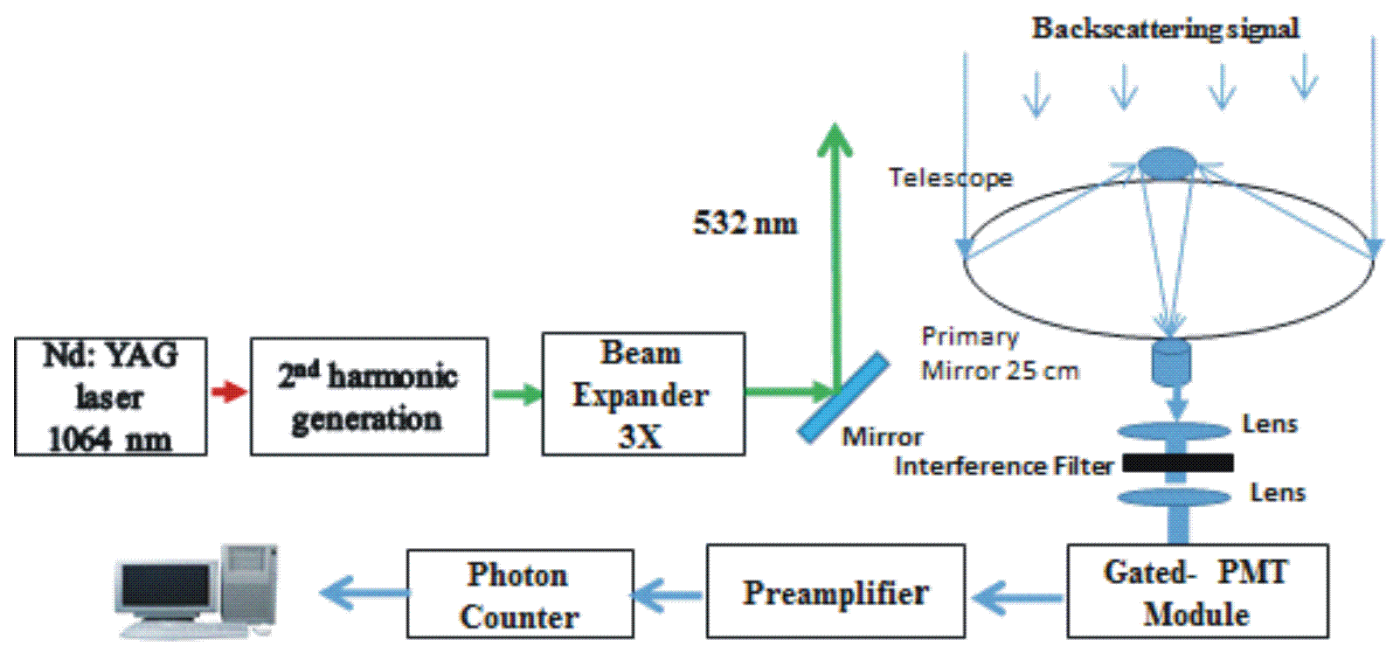

Fig. 1. Block schema of Rayleigh lidar system 
Table 1. Specification of our Rayleigh lidar system

\begin{tabular}{|l|l|}
\hline Transmitter & Receiver \\
\hline Laser Nd: YAG emitting at $532 \mathrm{~nm}$ & Telescope Schmidt - Cassegrain \\
- Energy per pulse (max): $180 \mathrm{~mJ}$ & • Diameter of telescope: $25 \mathrm{~cm}$ \\
- Pulse duration: $5 \mathrm{~ns}$ & • FOV: $1 \mathrm{mrad}$ \\
- Repetition rate: $10 \mathrm{~Hz}$ & - Gated-PMT module \\
- Beam divergence: $1 \mathrm{mrad}$ & • Photon Counter use digital Oscilloscope $8 \mathrm{bit}$ \\
\hline
\end{tabular}

With the acquisition of the weak backscattering signal from the stratosphere, a commonly encountered problem is the intense signal from the near range. This intense backscattering signal causes saturation for photomultiplier tube (PMT), which is a main optical detector at $532 \mathrm{~nm}$ wavelength. In order to solve this problem, we have developed a gated-PMT module operating in the photon-counting mode. Our gated-PMT module rejects the strong backscattering signal from the near range with a tunable cut-off range and receives the weak backscattering signal from the stratosphere, simultaneously. The backscattering photon is counted by a photon-counting system, which is a combination of the gated-PMT module, preamplifier, and digital oscilloscope. The time bin is initially set to the width of $8 \mathrm{~ns}$ that is corresponding to the spatial resolution of $1.2 \mathrm{~m}$. The lidar data are stored in the computer under format of *.txt by a developed program from Labview environment. The specifications of our Rayleigh lidar system are shown in Table 1.

\section{METHOD AND DATA ANALYSIS}

\section{III.1. Method}

The number density of atmospheric molecule can be derived from the backscattering signal by rearranging Rayleigh lidar equation [6]:

$$
\rho_{\text {mol }}(z)=C \times P_{\text {eff }}(z) \times z^{2} \times\left[\exp \left(-2 \tau_{\text {mol }}(z)\right)\right]^{-1},
$$

where $z$ is the height. $\mathrm{P}_{e f f}(\mathrm{z})$ is the effective lidar signal factor which is corrected by aerosol and absorption of ozone. $C$ is the normalization factor, it depends on parameters of lidar system (parameters of laser beam, the telescope area, the efficiency of lidar system) and parameters of atmospheric (the type of detected signal, the height resolution of measured data, the aerosol present level of the atmosphere). Because $C$ also includes the extinction of the lidar signal due to aerosols, in the fact that integrating in calculation of density and temperature is carried out at height that aerosols is not present. As $\mathrm{C}$ is unknown and difficult to determine accurately enough, only a relative molecule density profile can be derived from the lidar data alone. In order to obtain absolute molecule density value, $\mathrm{C}$ is quantified by normalizing $\rho_{m o l}(z)$ to pre-specified density at the normalization height $z_{\text {norm }}$ that must be chosen higher than aerosol-containing regions. $C$ derives from the equation (1):

$$
C=\rho_{\text {mod }}\left(z_{\text {norm }}\right) \times\left[P_{\text {eff }}\left(z_{\text {norm }}\right) \times z_{\text {norm }}^{2}\right]^{-1} \times \exp \left[-2 \tau_{\text {mol }}\left(z_{\text {norm }}\right)\right],
$$

where $\rho_{\text {mod }}\left(z_{\text {norm }}\right)$ is the molecule number density that is specified at the normalization height. The atmospheric molecular attenuation in the equation (1) is unknown but it can be calculated by the iterative method based on the equation (1) and the definition of the molecular attenuation as 
follows:

$$
\tau_{m o l}(\lambda, z)=\int_{0}^{z} \sigma_{m o l}(\lambda) \times \rho_{m o l}\left(z^{\prime}\right) d z^{\prime}
$$

In the first step, $\tau_{m o l}(z)=0$ is assumed for all height. In the second step, the $\rho_{\text {mol }}(z)$ is calculated in equation (1) from the last $\tau_{m o l}(z)$. In the third step, $\rho_{m o l}(z)$ is derived from the last step is used to calculate a new atmospheric molecular attenuation $\tau_{m o l}(z)$. Repeating steps 2 and 3 , both $\rho_{m o l}(z)$ and $\tau_{m o l}(z)$ will converge quickly in a few iterative steps.

Based on assumptions of the hydrostatic equilibrium and the ideal-gas law, the atmospheric temperature can be derived from the air molecule number density following the proposed method by A. Hauchecorne and M. Chanin (1980) by using a pre-specified tie-on reference temperature. The temperature is expressed by the following equation [6]:

$$
T(z)=\frac{\rho_{\text {mol }}\left(z_{r e f}\right)}{\rho_{\text {mol }}(z)} \times T\left(z_{r e f}\right)+\frac{M}{R \times \rho_{\text {mol }}(z)} \int_{z}^{z_{r e f}} \rho_{m o l}\left(z^{\prime}\right) \times g\left(z^{\prime}\right) d z^{\prime},
$$

where $T\left(z_{r e f}\right)$ is the tie-on reference temperature that get from other data at a reference height $z_{\text {ref }}$. The reference height is often chosen where the signal-to-noise ratio of lidar signal could be reliable. $M$ is the mean atmospheric molecular weight, $R$ is the molar gas constant, $g(z)$ is the gravitation acceleration.

Errors in the Rayleigh lidar temperature measurement originates from factors such as: aerosols scattering, uncertainties of ozone attenuation, selection of the tie-on temperature, signal noise.

Our previous investigation by lidar measurement had shown the top height of cirrus cloud in Hanoi located about 16km [9]. Therefore, effect of aerosol of ice crystal scattering is negligible above $20 \mathrm{~km}$ in our Rayleigh lidar signal.

The temperature error due to the uncertainties of ozone attenuation is given by the following equation [6]:

$$
\Delta T=\frac{\Delta \exp \left(-2 \tau_{O 3}\right)}{\exp \left(-2 \tau_{O 3}\right)}
$$

The error is caused by the selection of the tie-on temperature $\mathrm{T}\left(\mathrm{z}_{r e f}\right)$ can be derived from equation (4):

$$
\Delta T(z) \approx \frac{\rho\left(z_{r e f}\right)}{\rho(z)} \Delta T\left(z_{r e f}\right) .
$$

$\Delta T\left(z_{r e f}\right)$ is the uncertainty of tie-on reference temperature. It can estimate from the data of standard atmospheric model.

Our lidar system operates in the photon counting mode, so the photon noise follows the Poisson statistics. The error is caused by noise can be expressed by [6]:

$$
\Delta T(z) \approx \frac{T(z)}{\sqrt{m P_{(z)}}}
$$

where $m$ is number of laser pulses, $\mathbf{P}(\mathbf{z})$ is the backscattering photon counts. We can reduce noise error by sacrificing the spatial and temporal resolution by taking many bins from raw data or increasing integration time. 


\section{III.2. Data analysis}

The Rayleigh lidar system could be optimized through installing the appropriable parameters in real measurement by using the lidar signal. Each data file was generated by accumulating in 10 minutes corresponding to 6000 laser pulses. Our proposed procedure for analyzing lidar signals in order to obtain the temperature profile are schematically summarized in the flow chart in figure 2. The corrected lidar signal obtains from the raw signal by subtracting the background light. This corrected lidar signal is then multiplied by the square of range to get the correction-range signal. In order to examine the reliability of measurement, the correction-range signal profile is compared with molecule density profiles of the MSIS-90 atmosphere model in logarithmic scale. This examination allows us to reject measurements that are affected by signal-induced-noise phenomenon.

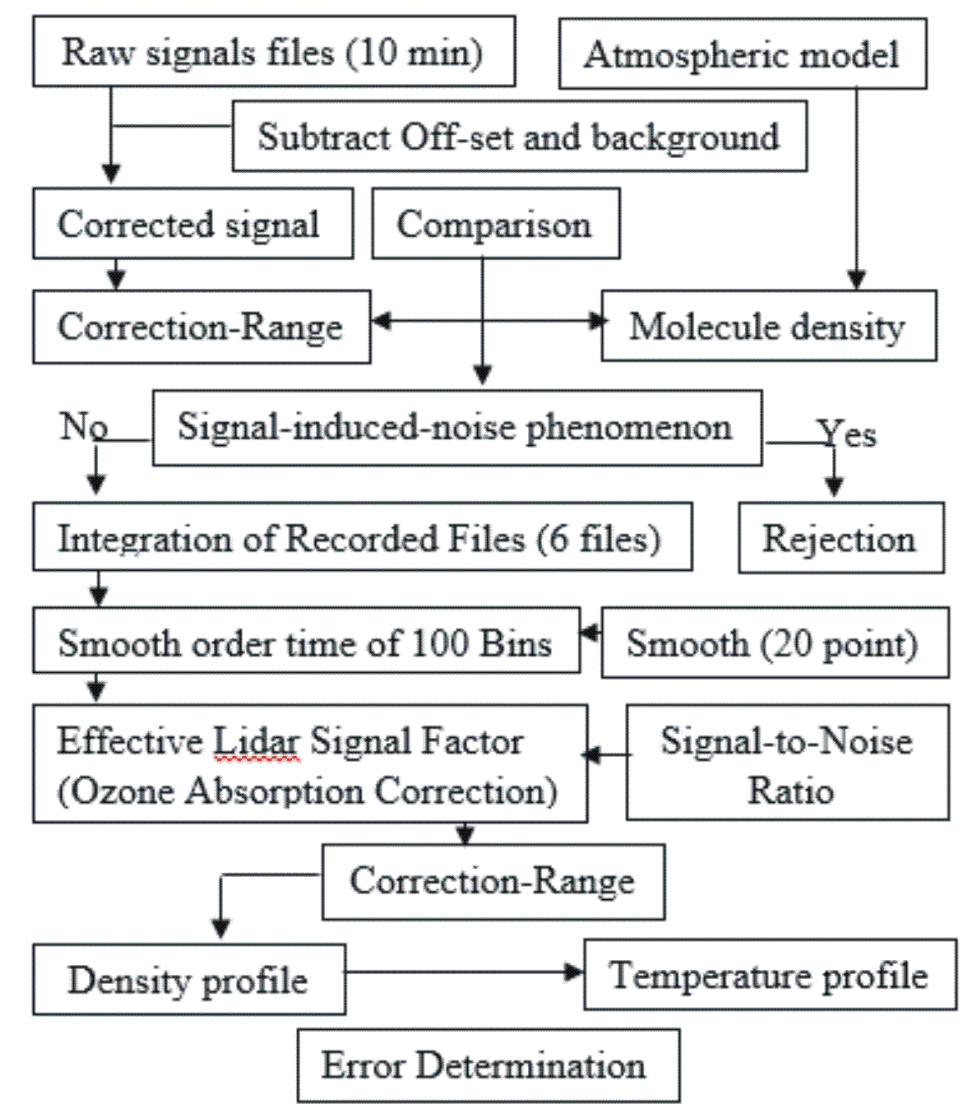

Fig. 2. Flow chart of temperature deviation from Rayleigh lidar signal

An example of integrated lidar signal file in 10 minutes is showed in Fig. 3. In order to increase the detected range and decrease the statistical error, we carried out integrations of six recorded signal files and smoothing order time of 100 range bins. That makes to 1 hour temporal and $120 \mathrm{~m}$ spatial profile resolutions. The lidar signal is smoothed 20 points in logarithmic scale following the weighted linear least square fit in order to decrease fluctuations. The effective lidar 
signal factor is derived after correction of ozone absorption. Because we do not have real heightresolved ozone concentration profile in the stratosphere above Hanoi, we adopted a reference ozone concentration profile from SAGE satellite (Source: NASA). The number density and the round-trip transmission of ozone showed in Fig. 4.

lidar signal integrate in 10 minute

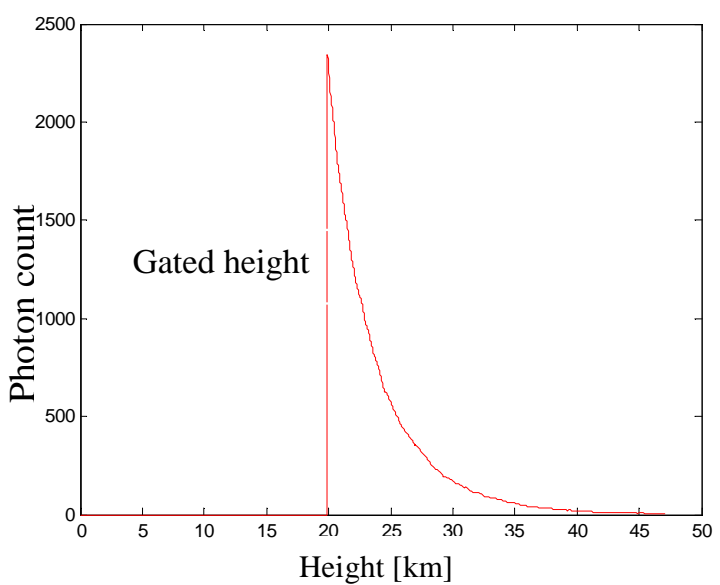

correction-range signal in 10 minute

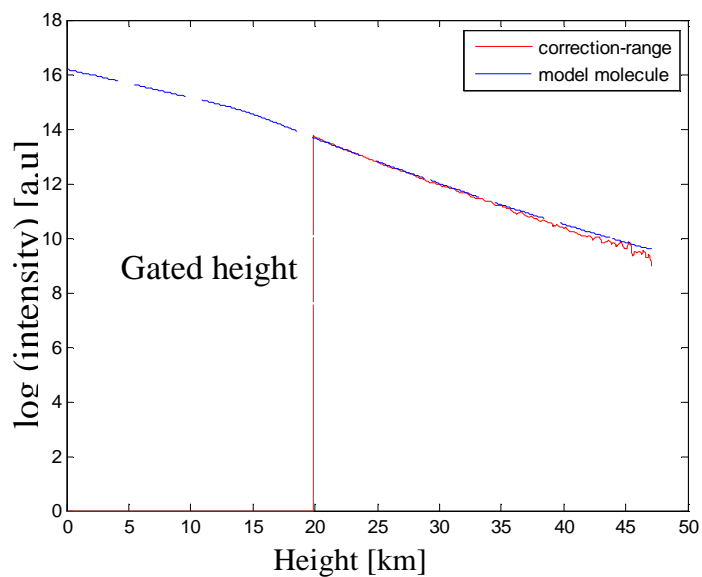

Fig. 3. Lidar signal integrated in 10 minutes (left), correction-range compared with model molecule profiles on logarithmic scale (right)
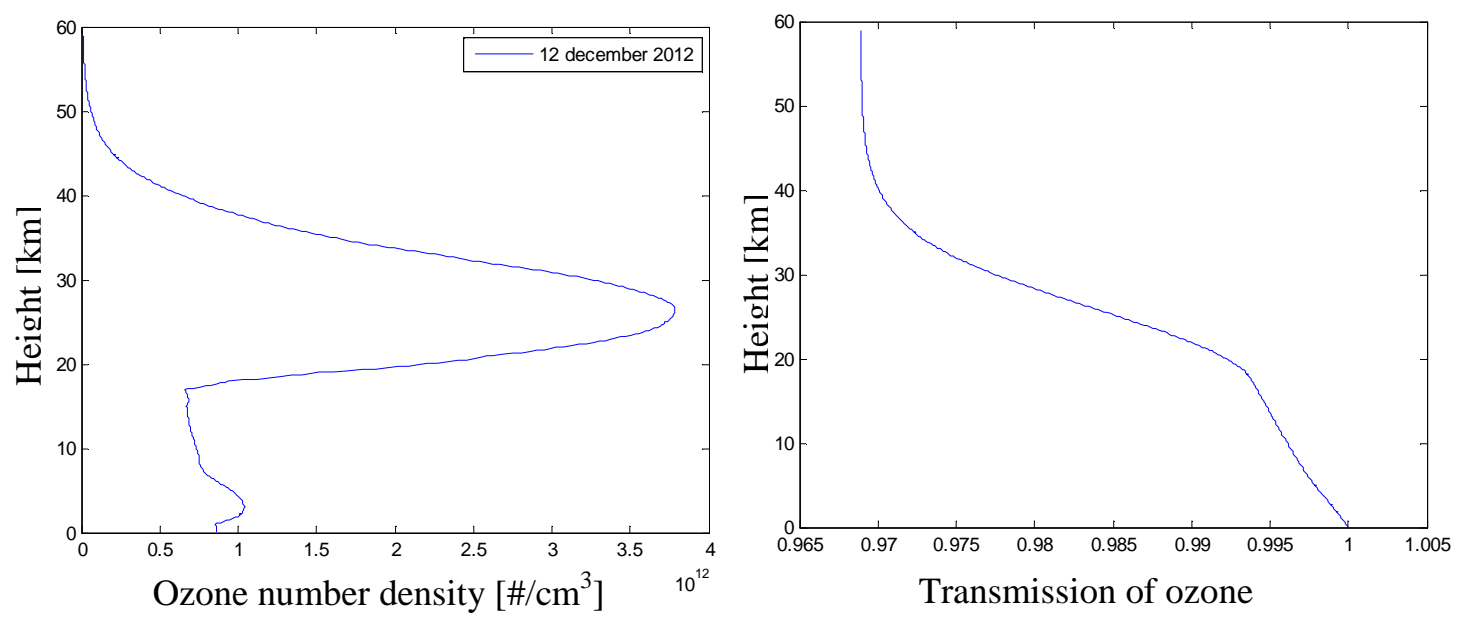

Fig. 4. Ozone concentration (Source: http://igaco-o3.fmi.fi/ACSO/) and the atmospheric round-trip transmission of ozone. 
The maximum detected range is determined based on the signal-to-noise ratio (SNR) by following equation [8]:

$$
S N R=\frac{P_{\text {signal }}}{\sqrt{P_{\text {signal }+2 P_{b g}}}}
$$

where, $P_{\text {signal }}$ is photon count after subtracting the background signal, $P_{b g}$ is background count. SNR has to be higher than 1. The correction-range lidar signal profile, the signal-to-noise ratio profiles of our measurement in 1 hour showed in Fig. 5. The absolute number density of air molecule obtained from the correction-range profile by normalizing to the density of the MSISE-90 atmospheric model at a reference point. The temperature profile is derived from the molecule number density following above the described method with the reference temperature from the MSIS-90 atmosphere model at the maximum signal height. Finally, temperature errors are estimated as the above method.
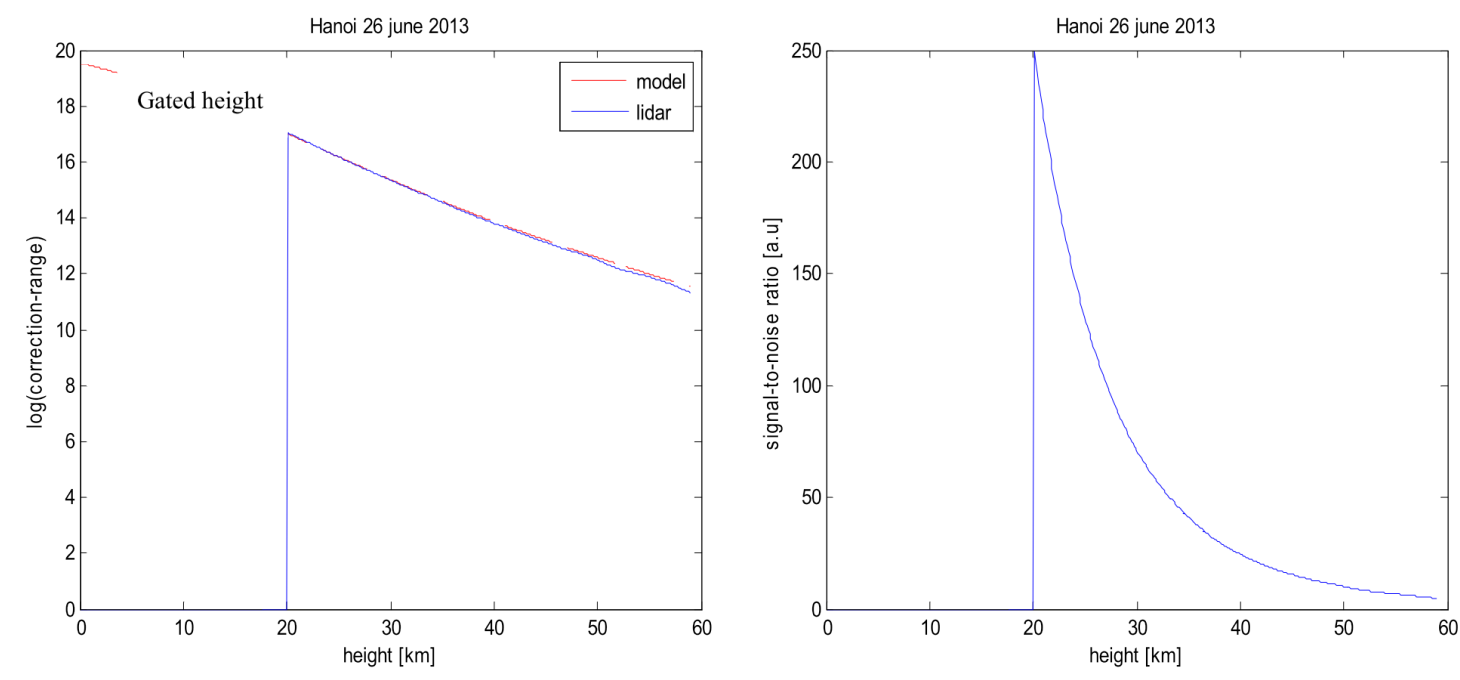

Fig. 5. Correction-range lidar signal profile in 1 hour (logarithmic scale) compared with the standard molecule atmospheric model and its signal-to-noise ratio (SNR) profiles

\section{RESULTS AND DISCUSSION}

The integrated lidar signal in 1 hour from 7 h50 PM to 8 h50 PM (local time) in $26^{\text {th }}$ June 2013 is used to derive the molecule number of density profile of stratosphere in Hanoi. This density profile and its errors are shown in figure 6 . The profile has the range resolution is $120 \mathrm{~m}$, the installed gated-height of $20 \mathrm{~km}$, and the maximum height of $57 \mathrm{~km}$ where the signal-to-noise ratio is higher than 6 . The density profile indicates that the maximum error of density is $0.9 \%$.

The lidar number density profile is compared with the molecule number density of the MSIS-90 atmosphere model by the density deviation ratio:

$$
R_{\rho}(z)=\frac{\left|\rho_{\text {model }}(z)-\rho_{\text {lidar }}(z)\right|}{\rho_{\text {model }}(z)} * 100 \%
$$


Where, $\rho_{\text {model }}(z)$ is the number density of model, $\rho_{\text {lidar }}(z)$ is the number density of lidar. The density deviation ratio profile is also shown on Fig. 6. The minimum deviation of the density is $0 \%$ at the reference height of $24 \mathrm{~km}$ and the maximum deviation of the density is $4.16 \%$ at 52 $\mathrm{km}$. The temperature profile depends only on the relative number density profile therefore it is independent of the normalization of the density profile at the norm height $z_{\text {norm }}$ in a first-order approximation.
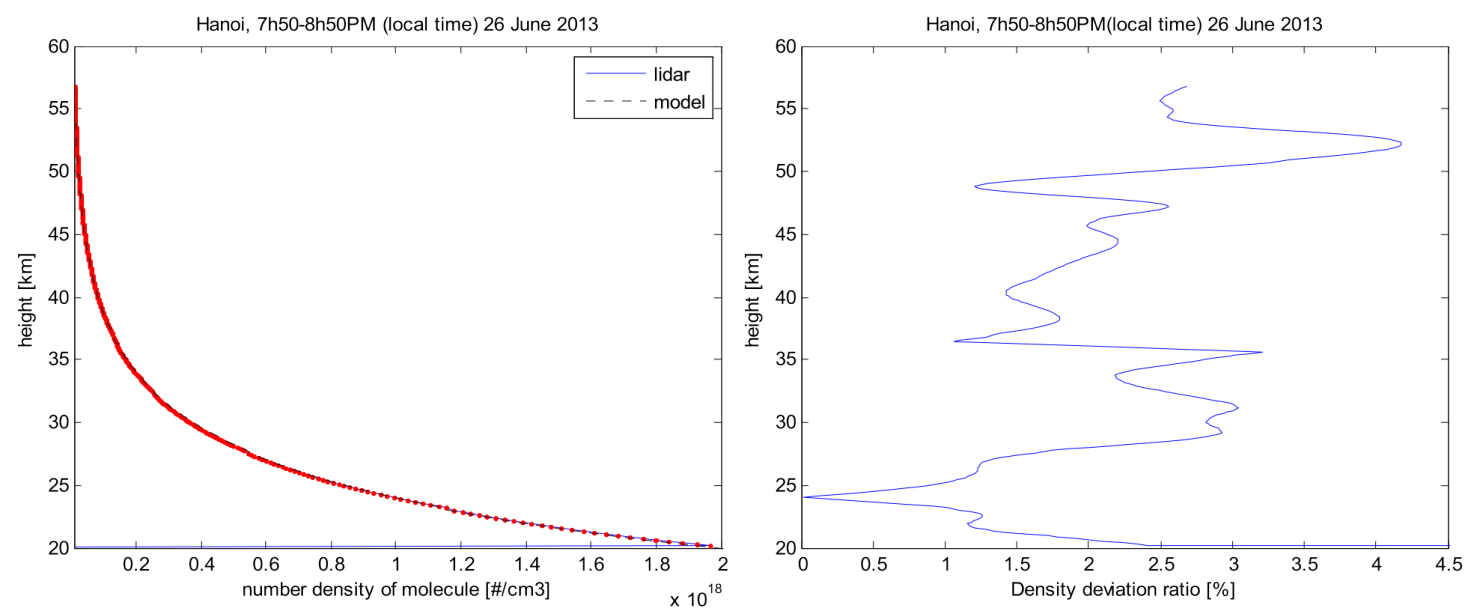

Fig. 6. The number density (left) and the density deviation ratio lidar-model and profiles derived from Rayleigh lidar measurements in Hanoi.
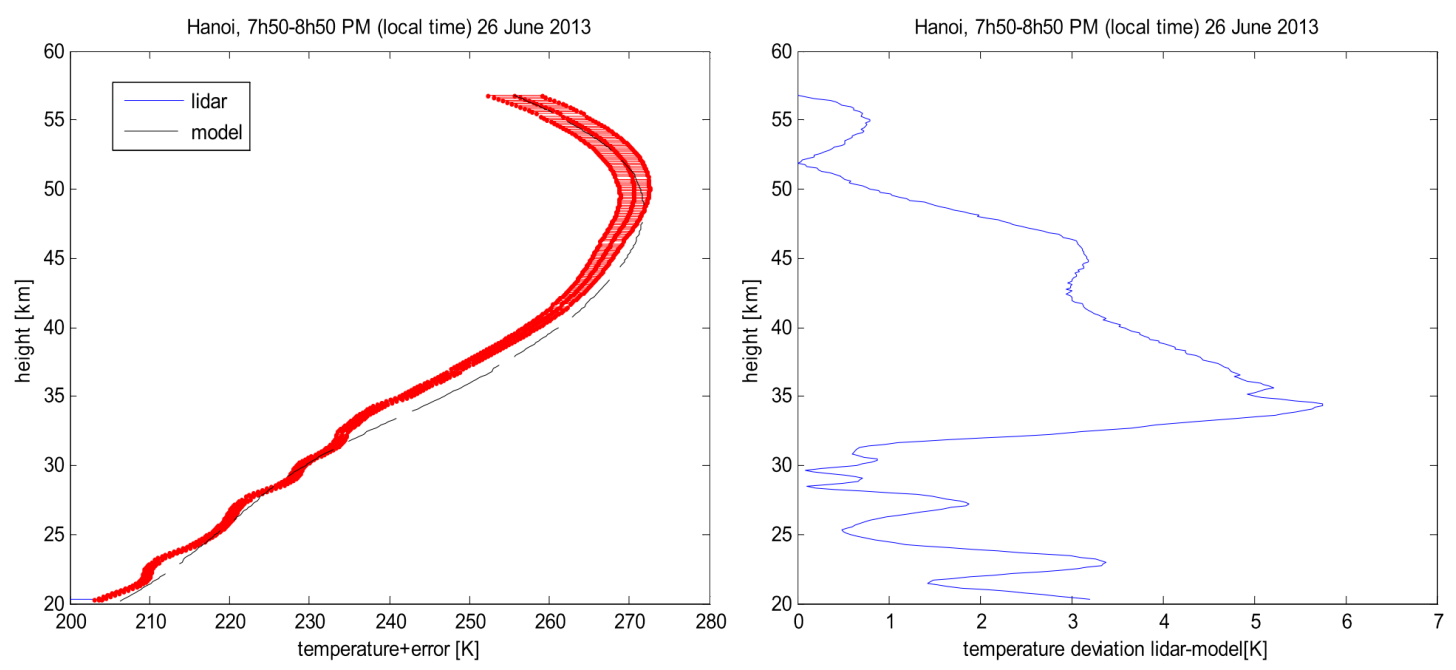

Fig. 7. The lidar temperature and errors profiles compare with model (left), the lidarmodel deviation profile is also estimate in figure (right). 
The temperature of the stratosphere in Hanoi is derived from the density shown in Fig. 7 (left). The error bars are also plotted in the same profile. Previously, the successive relative density profile is smoothed following the weighted linear least squares in the last $10 \mathrm{~km}$ to mitigate the distortion due to the rapid decay of backscattering signal. The temperature profile of the MSISE90 atmospheric model at the same day is also shown in the Fig. 7 and agreement between lidar and model temperature profiles is good. The uncertainty of the transmission of ozone is smaller than 0.002 that made the error of temperature is smaller $0.6 \mathrm{~K}$. The uncertainty of noise causes for the error of temperature that is smaller than $0.3 \mathrm{~K}$. The uncertainty of the tie-on reference temperature of the standard atmosphere model is $3 \mathrm{~K}$ that rapid decreases following range to be $0.8 \mathrm{~K}$ below $47 \mathrm{~km}$ and $0.1 \mathrm{~K}$ below $32 \mathrm{~km}$. The maximum total error of temperature is smaller than $3.4 \mathrm{~K}$ corresponding to $1.32 \%$.

Discrepancies between the lidar temperature and model temperature profiles showed in Fig. 7 (right). The main temperature difference between lidar and model happens in the range from 32 to $45 \mathrm{~km}$ and the maximum temperature difference is $5.75 \mathrm{~K}$ at $34.3 \mathrm{~km}$.

The temperature profile of the stratosphere indicates the information about the stratopause. This atmospheric region makes a division between the stratosphere and the mesosphere of the atmosphere. Structure and trends of temperature in the stratosphere relate directly the density of ozone because increasing of temperature in this atmospheric layer is due to existence of the ozone layer. Therefore, observation of the stratopause will reveal information about the characteristic of ozone in the atmosphere. The position and temperature of the stratopause in Hanoi from our Rayleigh lidar measurement are about $49.8 \mathrm{~km}$ and $270.6 \mathrm{~K}$, respectively. This value is a little higher than the stratopause from the model's profile. The position and the temperature of the stratosphere of the model are $49.1 \mathrm{~km}$ and $271.8 \mathrm{~K}$.

We have compared the position and temperature of the stratopause from our Rayleigh lidar measurement with the other Rayleigh lidar measurement in order to solidify the validation of our results. The stratopause height from our lidar measurement is compared with other lidar measurement in Guru Shikhar, Mount Abu, India (2439'17.34”N 72 ${ }^{\circ} 46^{\prime} 45.18^{\prime \prime}$ ) [10]. Their value is very close together. The mean height of the stratopause in lidar measurement in India is $48 \mathrm{~km}$ with error of $1.7 \mathrm{~km}$. The difference between two values may be due to difference position and time of lidar measurements.

The database of the number density and temperature profiles of the stratosphere in a long time could reveal the information about the structure, characteristics and the temperature trend of the atmosphere in Hanoi. The results will be reported in next publication.

\section{CONCLUSIONS}

The use of powerful Rayleigh lidar has allowed the measurements of the number density profile and the temperature profile of the stratosphere in Hanoi in nightly. These profiles had the spatial resolution of $120 \mathrm{~m}$ and the temporal resolution of 1 hour In measured profiles, the bottom height and the top height were determined at $20 \mathrm{~km}$ and $57 \mathrm{~km}$, respectively. The number density and the temperature profiles of lidar measurement showed good agreement with the number density and the temperature profile from the MSISE-90 atmospheric model. The maximum error of the number density was determined to be $\pm 0.9 \%$ and the maximum error of temperature is determined to be $\pm 3.4 \mathrm{~K}$. The maximum temperature difference between lidar measurement and the model was $5.75 \mathrm{~K}$ at $34.3 \mathrm{~km}$. The temperature profile from lidar measurement also indicated 
that the stratopause height and temperature are about $49.8 \mathrm{~km}$ and $270.58 \mathrm{~K}$. The characteristics and structures of the stratosphere in Hanoi will be reported in the next publication.

\section{ACKNOWLEDGEMENTS}

The authors would like to thank Vietnam Academy of Science and Technology, the program KC01.26/06-10 for support. Financial assistance from National Foundation for Science and Technology (NAFOSTED) under contract 103.08-2010.26 is greatly acknowledged.

\section{REFERENCES}

[1] D. Rind, A. Lacis, Survey in Geophysics 14 (2) (1993) 133-165.

[2] V. Ramaswamy, M.-L. Chanin, J. Angell, J. Barnett, D. Gaffen, M. Gelman, P. Keckhut, Y. Koshelkov, K. Labitzke, J.-J. R. Lin, A. O'Neill, J. Nash, W. Randel, R. Rood, K. Shine, M. Shiotani, and R. Swinbank, Review Geophysics, 39 (1) (2001) 71-122, doi:10.1029/1999RG000065.

[3] Alain Hauchenorne, Marie Lise Chanin, Geophysical Research Letter Vol 7(8) (1980) 565-568

[4] T. Shibata, M. Kobuchi, M. Maeda, Applied Optics 25 (1986) 685-688

[5] Micheal R. Gross, Thomas J. McGee, Richard S. Ferrare, Upendra N. Singh, and Patrick Kimvilakani, Applied Optics 36 (24) (1997) 5987-5995

[6] W. N. Chen, C. C. Tsao, J. B. Nee, Journal of Atmospheric and Solar-Terrestrial Physics 66 (2004) $39-49$.

[7] Jaya Khanna, Justin Bandoro, R. J. Sica, and C. Thomas McElroy, Applied Optics 51 (33) (2012) 7945-7952.

[8] B. Heese, H. Flentje, D. Althausen, A. Ansman, and S. Frey, Atmospheric Measurement Techniques 3(4) (2010) 3907-3924.

[9] Bui Van Hai, Dinh Van Trung, Nguyen Xuan Tuan, Dao Duy Thang, and Nguyen Thanh Binh, Communications in Physics 22 (2012) 357-364.

[10] Chandra, Som Sharma, Y.B Acharya and A. Jayaraman, J. Ind. Geophys. Union 9 (4) (2005) 279-298. 